\title{
Rancang Bangun Sistem Informasi Rent Car Dengan Pengunaan Aplikasi Online
}

\author{
Ari Abdilah', Badariatul Lailiah², Rabiatus Sa'adah ${ }^{3}$ \\ ${ }^{1,2}$ Program Studi Teknologi informasi, Fakultas Teknik dan Informatika, Universitas Bina Sarana Informatika, \\ J1. Kramat Raya No.98, Jakarta Pusat, DKI Jakarta 10450, Indonesia \\ ${ }^{3}$ Program Studi Rekayasa Perangkat Lunak, Fakultas Teknik dan Informatika, Universitas Bina Sarana \\ Informatika, \\ J1. Kramat Raya No.98, Jakarta Pusat, DKI Jakarta 10450, Indonesia \\ e-mail: ${ }^{1}$ ari.aab@bsi.ac.id, ${ }^{2}$ badariatul.bdl@bsi.ac.id, ${ }^{3}$ rabiatus.rbh@bsi.ac.id
}

Artikel Info : Diterima : 09-07-2021 | Direvisi : 16-07-2021 | Disetujui : 23-07-2021

\begin{abstract}
Abstrak - PT. Rent Car adalah perusahaan yang bergerak pada jasa penyewaan mobil (rent a car). Didalam proses pencatatan data, petugas masih melakukan dengan cara menulis data pada sebuah buku, sehingga dinilai kurang efektif juga menyulitkan petugas dalam membuat laporan. Pada saat pelanggan ingin menyewa mobil yang mereka inginkan, tak jarang mereka merasa kecewa karena mobil yang terbatas dan tidak mengetahui informasi tentang mobil yang ingin disewa. Penelitian ini menggunakan metode pengumpulan data dan metode pengembangan sistem. Oleh karena itu, PT. Rent Car membutuhkan sebuah sistem aplikasi penyewaan yang mampu mengintegrasikan sistem penyewaan konvensional menuju ke arah sistem penyewaan online. Software yang digunakan dalam merancang sistem informasi berbasis web ini yaitu bahasa pemrograman PHP Script dan untuk database menggunakan $M y S Q L$
\end{abstract}

Kata Kunci : website, Rent, $M y S Q L$

Abstracts - PT. Rent Car is one of the companies engaged in the rental car (rent a car). In the process of recording data, officials are still doing by entering the data into the general ledger, so it is considered less effective also make it difficult for the officer to make a report. When a customer wants to rent a car they want, they often feel disappointed because the car is limited and does not know the information about the car that wants to hire. The method used in this research includes methods of data collection and system development methods. Therefore, PT. Rent Car need a rental application system that can integrate the conventional rental system toward online rental system. And specification of software used to design a web-based information system that is using the programming language PHP scripts and to use MySQL database.

Keywords : website, Rent, $M y S Q L$

\section{PENDAHULUAN}

PT. Rent Car adalah perusahaan yang bergerak di bidang penyediaan jasa sewa mobil (rent a car). Didalam proses pencatatan data, petugas masih melakukan dengan cara menulis data pada sebuah buku, sehingga dinilai kurang efektif juga menyulitkan petugas dalam membuat laporan. Pada saat pelanggan ingin menyewa mobil yang mereka inginkan, tak jarang mereka merasa kecewa karena mobil yang terbatas dan tidak mengetahui informasi tentang mobil yang ingin disewa. Menurut Heriyanto (Heriyanto, 2018) Rental mobil adalah bisnis penyediaan jasa sewa mobil, untuk mempermudah konsumen dalam melakukan penyewaan mobil. penelitian ini menggunakan metode yang dilakukan dalam penelitian ini yaitu metode pengumpulan data dan metode pengembangan sistem. Oleh karena itu, PT. Rent Car membutuhkan sebuah sistem aplikasi penyewaan yang mampu mengintegrasikan sistem penyewaan konvensional menuju ke arah sistem penyewaan online .

Dengan sistem penyewaan ini juga diharapkan mampu meningkatkan pendapatan dalam penyewaan mobil oleh konsumen. Aplikasi penyewaan kendaraan merupakan salah satu teknik pengolahan data yang berkaitan dengan aktivitas mencatat serta memperbarui data kendaraan. (Nur et al., 2021).

Dalam mengatasi permasalahan tersebut, sebelumnya PT. Rent Car sebagai perusahaan yang menyediakan

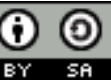

$$
105
$$

This work is licensed under a Creative Commons Attribution-ShareAlike 4.0 International License. 
jasa khususnya penyewaan mobil harus memiliki sebuah manajemen yang baik agar pengelolaan bisnis dapat berjalan dengan baik. Selain itu dibutuhkan pula sebuah aplikasi pada sistem penyewaan yang mampu mengintegrasikan penyewaan konvensional menuju arah konsep penyewaan secara online. Konsep tersebut akan dibuat dengan beberapa aplikasi berbasis web, salah satunya adalah penyediaan portal rental mobil berbasis website.

Fungsi kerja dari website sendiri tidak hanya berperan sebagai media penyampaian informasi saja namun bisa menjadi aplikasi untuk pendukung sebuah sistem. Seiring dengan perubahan penggunaan internet sebagai media marketing dan pusat informasi yang mudah di akses dan tidak terbatas oleh jangkauan jarak dan waktu.

\section{METODE PENELITIAN}

Teknik pengumpulan data adalah serangkaian kegiatan atau cara untuk mendapatkan data atau informasi dari objek yang diteliti (Napiah et al., 2020). Adapun metode yang gunakan sebagai berikut:

A. Metode Pengumpulan Data

1. Observasi

Penulis melakukan pengamatan langsung kedalam bagian administrasi, mengamati sistem yang sedang berjalan didalam kegiatan bisnis penyewaan mobil yang ada di PT. Rent Car.

2. Wawancara

Melakukan tanya jawab dengan Bapak Ardian Pratama Putra selaku Manajer yang berperan didalam kegiatan bisnis penyewaan tersebut. Penulis meminta keterangan tentang sistem administrasi yang berjalan pada kegiatan bisnis saat ini, dan berpendapat mengenai sistem informasi administrasi penyewaan mobil berbasis website yang ingin dibuat untuk diterapkan dalam kegiatan bisnis rental mobil.

3. Studi Pustaka

Penulis mengumpulkan informasi melalui beberapa buku dan jurnal sebagai referensi dan sumber yang berbeda, yang diidentifikasi dengan subjek pembahasan skripsi ini.

B. Model Pengembangan Sistem

Adapun metode yang digunakan pada perancangan dan implementasi sistem meliputi beberapa proses yaitu :

1. Analisa Kebutuhan Sistem

2. Desain

3. Code Generation

4. Testing

5. Support

C. Konsep Dasar Model Pengembangan Sistem

1. Metode Waterfall

SDLC air terjun waterfall model dalam pengembangan sistem informasi eksekutif penduduk metode penelitian yang digunakan adalah metode deskriptif (Prasetyo \& Putra, 2021). Metode waterfall atau air terjun menyediakan pendekatan alur hidup pemrograman yang berurutan mulai dari tahap pemecahan, perencaan, pengkodean, pengujian, dan pendukung. Berikut merupakan gambaran model air terjun :

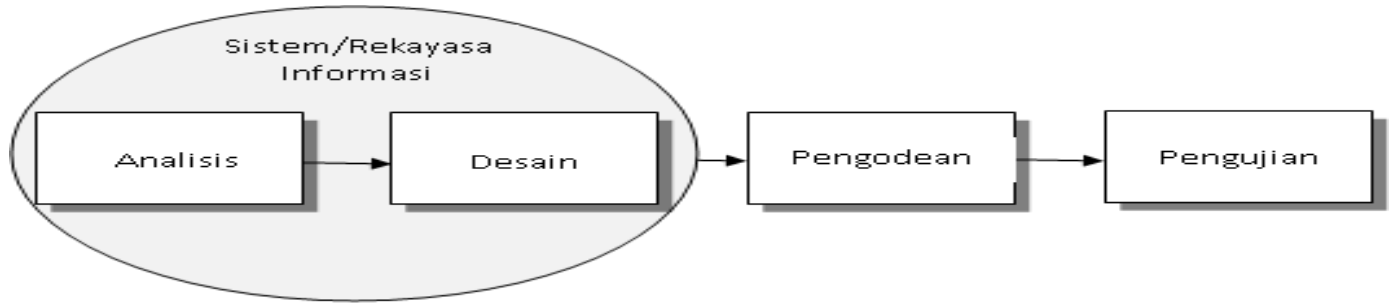

Gambar 1. Model Waterfall

Sumber : (Rosa Ariani, 2016) 
2. Black Box Testing

Black Box Testing merupakan pengujian perangkat lunak dari yang dilakukan dengan cara mengamati hasil eksekusi tanpa menguji desain dan kode program. Pengujian ini diusulkan untuk memutuskan apakah kapasitas, sumber data, dan hasil produk sesuai dengan spesifikasi yang diperlukan atau sesuai dengan kerangka kerja saat ini ( Rosa \& Shalahuddin, 2016). Eksperimen yang dilakukan untuk melakukan Black Box Testing harus kasus benar dan kasus salah, misalnya untuk kasus siklus login, percobaan yang dilakukan adalah

A. Klien memasukkan username dan password secara efektif

B. Klien memasukkan username dan password yang tidak dapat diterima, misalnya, nama pengguna benar namun password salah, atau sebaliknya, atau keduanya salah.

D. UML (Unifield Modelling Language)

1. Pengertian UML

Unifield Model Language (UML) adalah salah satu perangkat yang digunakan untuk pengembangan kerangka kerja berbasis objek (Ardian et al., 2018). Kemampuan UML untuk melakukan demonstrasi, dan penggunaan UML tidak terbatas pada prosedur tertentu, meskipun sebenarnya UML paling sering digunakan dalam metodologi berorientasi objek.

\section{Diagram UML}

Dalam perkembangan prosedur pemrograman berorientasi objek, bahasa pemrograman yang dinormalisasi muncul untuk membuat pemrograman menggunakan metode pemrograman berbasis objek, khususnya Unifield Model Language (UML). Pemanfaatan UML ada mengingat kebutuhan tampilan visual dalam menentukan, menggambarkan, merakit, dan mendokumentasikan kerangka pemrograman (Syarif \& Nugraha, 2020). UML merupakan bahasa visual untuk menampilkan dan menyampaikan tentang suatu kerangka kerja dengan memanfaatkan grafik dan tulisan pendukung lainnya. UML hanya berfungsi untuk menampilkan, sehingga pemanfaatan UML tidak terbatas pada prosedur tertentu, meskipun sebenarnya UML paling banyak digunakan dalam teknik berorientasi objek (Haidar et al., 2021).

A. Use case Diagram

Use case Diagram adalah pemodelan untuk melakukan sistem informasi yang akan dibuat. Use case menggambarkan koneksi antara satu klien dengan klien lainnya dengan kerangka data yang akan dibuat. Use case digunakan untuk mengetahui kapasitas-kapasitas yang ada pada suatu situasi data dan siapa yang memiliki hak untuk memanfaatkan kapasitas tersebut, syarat penamaan untuk use case adalah bahwa nama tersebut berkarakteristik benar-benar dipahami (Rosa Ariani, 2016).

B. Activity Diagram

Activity Diagram adalah suatu aktivitas yang menggambarkan proses kerja (workflow) dari suatu kerangka kerja atau interaksi bisnis atau menu yang terdapat dalam perangkat lunak (Alfarisy, n.d.).

C. Component Diagram

Component Diagram dibuat untuk menunjukkan hubungan dan kondisi di antara bermacam-macam komponen dalam suatu sistem. Component diagram berpusat di sekitar komponen system yang diperlukan dan ada dalam system (Rosa Ariani, 2016).

D. Deployment Diagram

Deployment diagram menunjukkan pengaturan komponen dalam proses eksekusi aplikasi. Deployment diagram juga dapat digunakan untuk menampilkan kerangka tambahan (embedded system) yang menggambarkan rancangan sistem(Rosa Ariani, 2016).

E. ERD (Entity Relationship Diagram)

Pemodelan awal basis data yang yang paling sering digunakan adalah menggunakan Entity Relationship Diagram (ERD). ERD adalah suatu alat informasi penting yang akan membantu memilah informasi secara berurutan ke dalam elemen-elemen dan mengkarakterisasi hubungan antar entitas. (Juniardi Dermawan1, 2017)

\section{HASIL DAN PEMBAHASAN}

Sistem pemesanan secara online berbasis web dimana penyewa dan pemilik sewa tidak bertatap muka secara langsung. Calon penyewa melakukan penyewaan melalui media browser. Berikut ini spesifikasi kebutuhan (system requirement) dari sistem e-commerce.

Halaman Pelanggan :

A1. Pelanggan harus login terlebih dahulu.

A2. Pelanggan dapat login dengan account yang telah dibuat apabila ingin melakukan penyewaan di lain hari.

A3. Pelanggan bisa memilih mobil berdasarkan kategori setelah login.

A4. Pelanggan bisa memilih mobil yang akan disewa dan ditambahkan ke keranjang belanja.

A5. Pelanggan dapat memilih menggunakan jasa supir atau tidak

A6. Pelanggan dapat mencetak bukti penyewaan.

A7. Pelanggan dapat melakukan konfrimasi pembayaran via web. 
A8. Pelanggan dapat melakukan checkout.

Halaman Administrator :

B1. Administrator dapat mengelola data kendaraan.

B2. Administrator dapat mengelola data content.

B3. Administrator dapat mengelola data pelanggan.

B4. Administrator dapat mengelola data transaksi.

B5. Administrator dapat mengelola akun pengelola dan pelanggan.

1. Desain Sistem (UML)

A. Use case Diagram

Use case menggambarkan sebuah interaksi antara user satu dengan user lainnya dengan sistem informasi yang akan dibuat. Setiap use case dapat dideskripsikan dalam dokumen yang disebut dengan dokumen flow of event (Nur et al., 2021). Struktur dokumen use case ini bermacam-macam, tetapi umunya deskripsi memiliki beberapa unsur diantaranya :

1. Brief Description (deskripsi singkat)

2. Actor yang terlibat

3. Precondition yang penting bagi use case untuk memulai

4. Deskripsi rinci dari aliran kejadian yang mencangkup main flow, dari kejadian ini bisa dirinci menjadi sub flow dan alternatif flow

Berikut ini merupakan use case diagram dari sistem penjualan pakaian yang diusulkan :

a. Use case Diagram Belanja Online Halaman Pelanggan

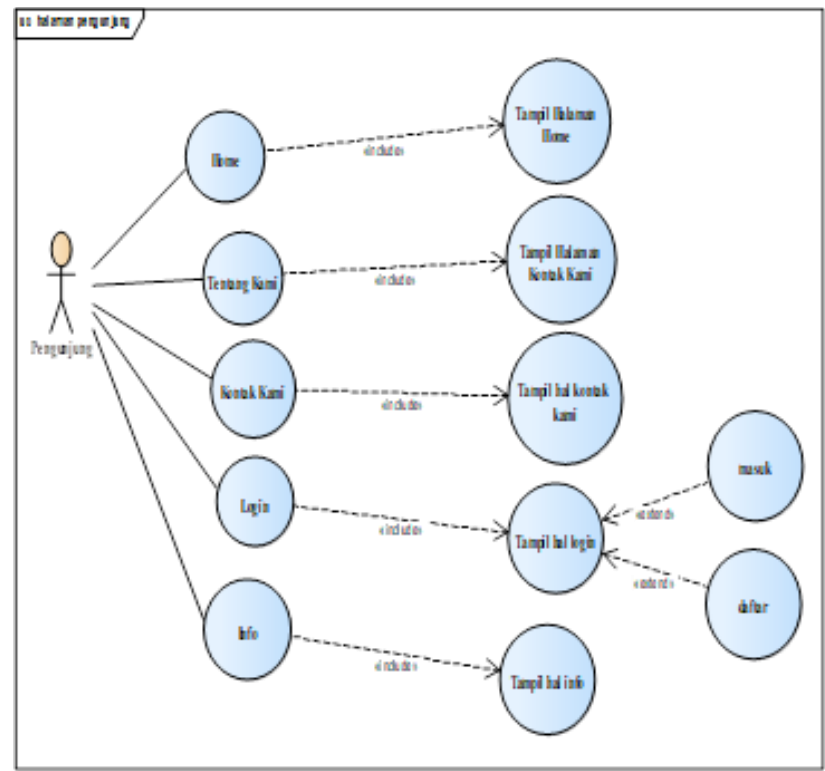

Gambar 2. Use case Diagram Sewa Mobil Online Halaman Pengunjung Sumber : Hasil Penelitian (2020) 
Computer Science (CO-SCIENCE)

Volume 1 No. 2 Juli 2021 | E-ISSN: 2774-9711

b. Use case Diagram Belanja Online Halaman Admin

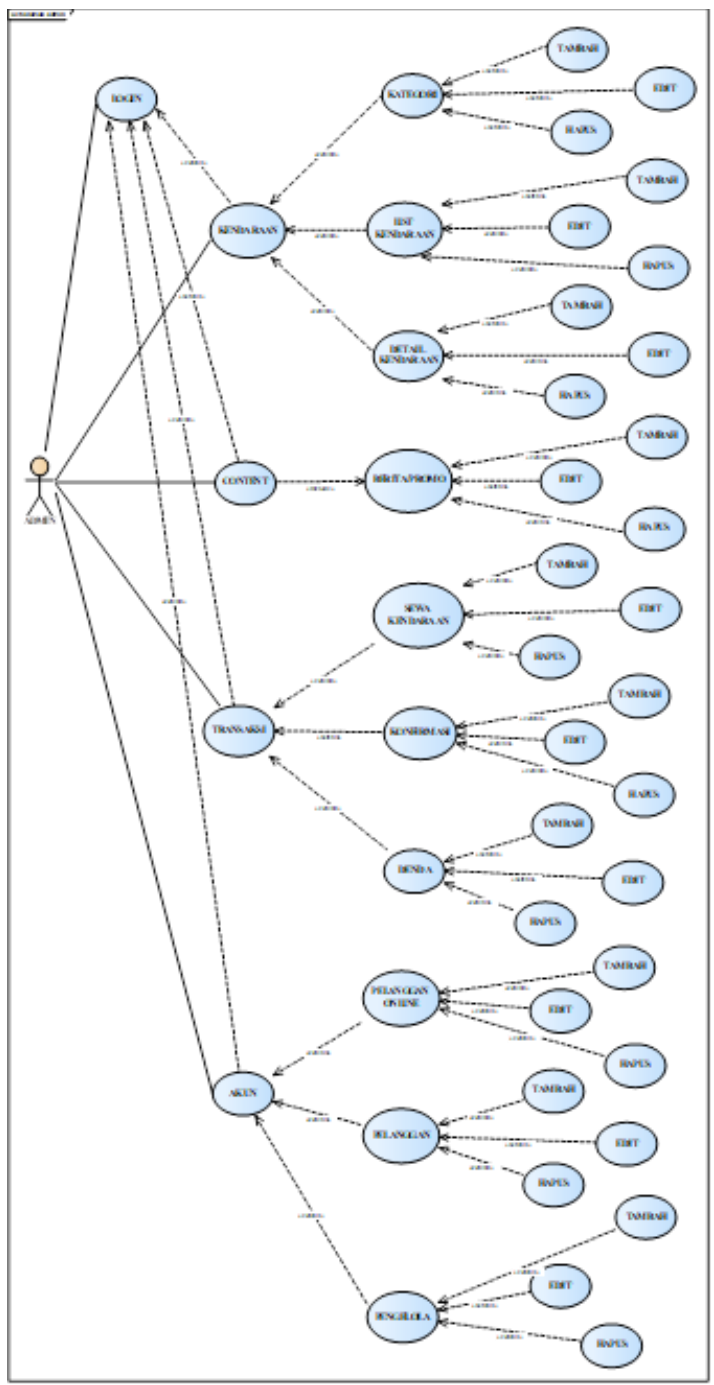

Gambar 3. Usecase Diagram Sewa Mobil Online Halaman Admin Sumber : Hasil Penelitian (2020)

\section{B. Component Diagram}

Component Diagram menggambarkan menggambarkan struktur dan hubungan antar komponen pemrograman, termasuk kondisi. Bagian pemrograman adalah modul yang berisi kode, keduanya berisi source kode maupun bimary kode baik library maupun executable, keduanya muncul pada compile time, link time maupun run time. Pada umumnya bagian-bagian diagram memiliki beberapa kelas dan package, tetapi juga dapat sebagai antarmuka, yang merupakan berbagai layanan yang diberikan oleh suatu segmen ke segmen yang lainnya. 


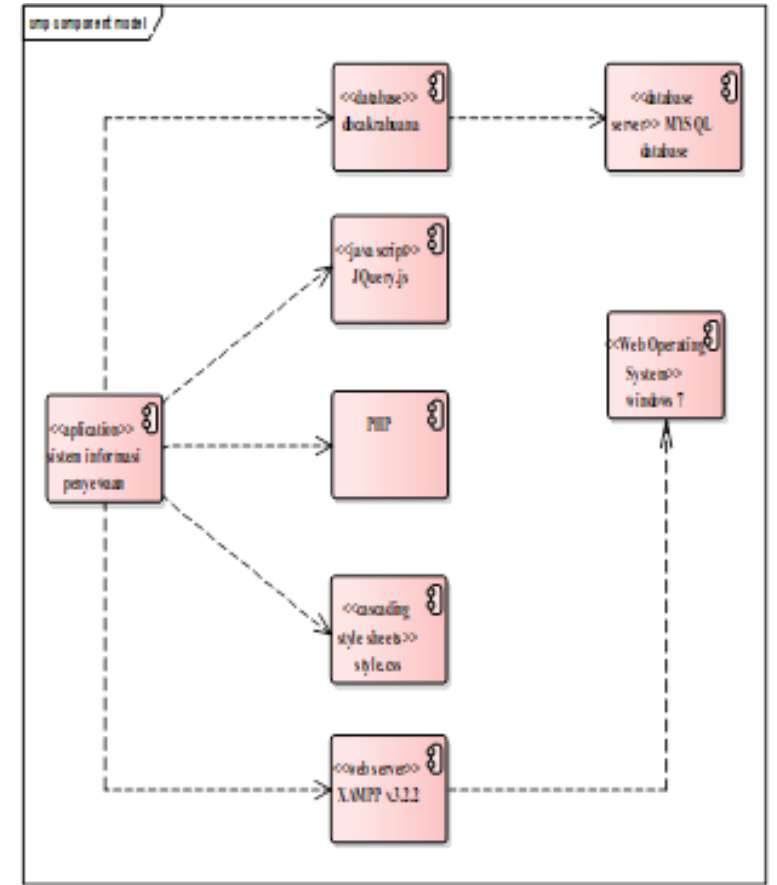

Gambar 4. Component Diagram Sistem Penjualan Online Sumber : Hasil Penelitian (2020)

\section{Deployment Diagram}

Deployment/physical Diagram menggambarkan menggambarkan suatu segmen yang disirkulasikan ke dalam suatu kerangka dasar, dimana segmen tersebut berada (pada mesin, server atau piranti keras apa) bagaimana kapasitas jaringan pada lokasi tersebut, spesifikasi server, dan hal-hal lain yang bersifat fisik. Sebuah node adalah server, workstation atau piranti keras lain yang digunakan untuk mendistribusikan komponen dalam lingkungan sebenarnya.

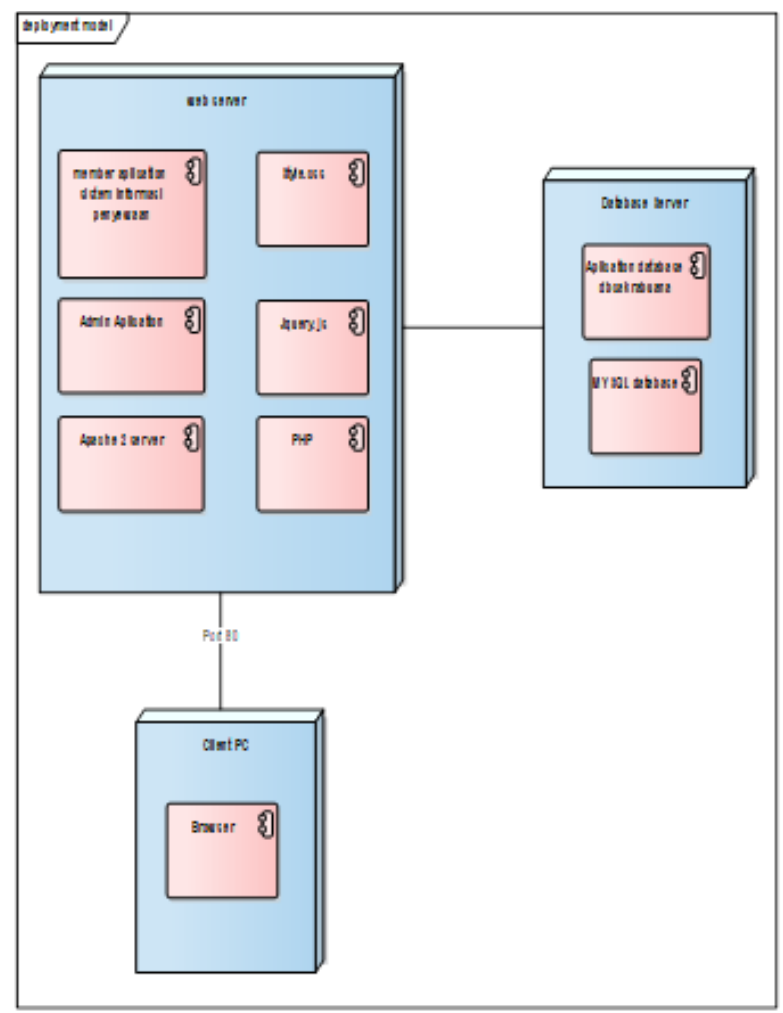

Gambar 5. Deployment Diagram Penyewaan Online Sumber : Hasil Penelitian (2020) 


\section{Computer Science (CO-SCIENCE)}

Volume 1 No. 2 Juli 2021 |E-ISSN: 2774-9711

2. Tampilan Program

A. Tampilan Halaman Utama

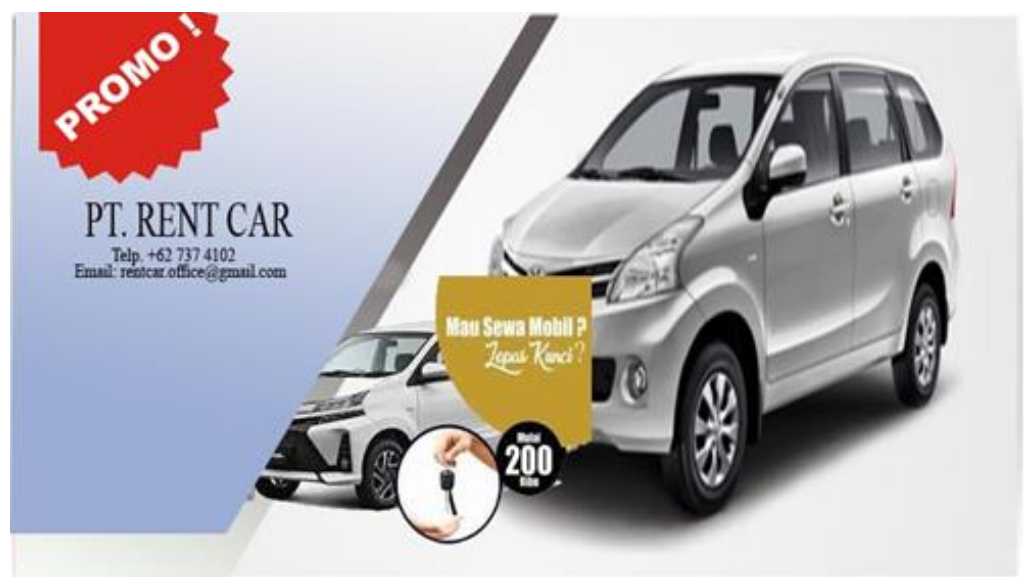

Gambar 6. Tampilan Website Halaman Utama Sumber : Hasil Penelitian (2020)

B. Tampilan Form Login pelanggan

\section{LOGIN FORM}

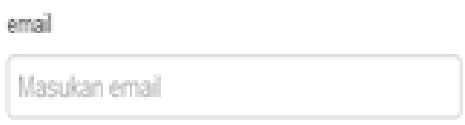

Passwerd

masukan password

Masuk Daftar

Gambar 7. Tampilan Login Pelanggan Sumber : Hasil Penelitian (2020)

C. Tampilan Menu Admin

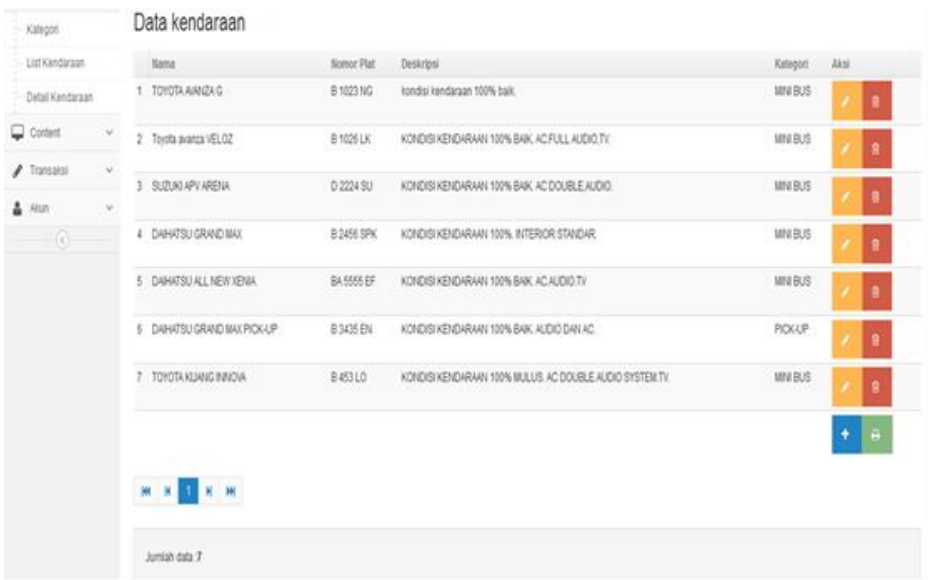

Gambar 8. Tampilan Halaman Utama Admin Sumber : Hasil Penelitian (2020) 


\section{KESIMPULAN}

Berdasarkan penelitian yang telah penulis lakukan pada bab sebelumnya, penulis dapat menyimpulkan bahwa, melalui sistem informasi persewaan mobil berbasis web, pelanggan diharapkan dapat memperoleh informasi tentang kendaraan yang ingin mereka sewa tanpa harus datang langsung ke tempat tersebut, dengan menerapkan Sistem Informasi Pelanggan berbasis Web bisa mendapatkan respon yang lebih cepat, tepat dan akurat serta mempermudah dan mempercepat bagian Administrator dalam proses pembuatan laporan

Berdasarkan pengalaman yang diperoleh saat melakukan penelitian di PT. Rent Car, penulis mempunyai saransaran yang semoga bermanfaat bagi perkembangan dan kemajuan perusahaan, yaitu sebagai berikut :

1. Antarmuka harus dibuat lebih menarik dan user friendly untuk menarik lebih banyak pengunjung.

2. Perlu melatih Administrator sebelum sistem diimplementasikan agar dalam aplikasi website Sewa Mobil Cakra Buana Unggul tidak terjadi kesalahan dalam pengelolaan data dan transaksi.

3. Mengingat pentingnya keamanan data, maka perlu memperhatikan keamanan dan backup data dalam pengembangan selanjutnya.

4. Penyampaian informasi yang up to date dapat meningkatkan citra dan kinerja perusahaan dalam mengelola bisnis rental mobil.

\section{REFERENSI}

Alfarisy, M. H. dan A. D. (n.d.). Rancang Bangun Sistem Informasi Penyewaan Mobil pada Abu.pdf.

Ardian, D., Larasati, P. D., \& Irawan, A. (2018). Perancangan Sistem Informasi Aplikasi Rental Mobil Menggunakan Java Netbeans dan MySQL pada Perusahaan Dean's Car Rent. Applied Information System and Management (AISM), 1(1). https://doi.org/10.15408/aism.v1i1.8670

Haidar, P., Dhika, H., \& Habibie, M. T. (2021). Perancangan Sistem Informasi Penyewaan Mobil di Videl Rental Berbasis Java. Jurnal Riset Dan Aplikasi Mahasiswa Informatika (JRAMI), 2(02), $213-219$. https://doi.org/10.30998/jrami.v2i02.825

Heriyanto, Y. (2018). Perancangan Sistem Informasi Rental Mobil Berbasis Web Pada PT.APM Rent Car. Jurnal Intra-Tech, 2(2), 64-77.

Juniardi Dermawan1, S. H. (2017). IMPLEMENTASI MODEL WATERFALL PADA PENGEMBANGAN SISTEM INFORMASI PERHITUNGAN NILAI MATA PELAJARAN BERBASIS WEB PADA SEKOLAH DASAR AL-AZHAR SYIFA BUDI JATIBENING. Notes and Queries, s5-VII(159), 37. https://doi.org/10.1093/nq/s5-VII.159.37-a

Napiah, M., Raharjo, M., Putra, J. L., Heristian, S., \& Leksono, I. N. (2020). Rancang Sistem Penyajian Bank Soal Untuk Jenjang Sekolah Menengah Atas Berbasis Web. Jurnal Infortech, 2(2), 133-138. https://doi.org/10.31294/infortech.v2i2.9022

Nur, S., Putri, I., Zaeni, M., Jasmiati, D., Nirmala, E., \& Kusyadi, I. (2021). Analisa dan Perancangan Aplikasi Sistem Penyewaan Kendaraan berbasis Java. 4(2), 103-109. https://doi.org/10.32493/jtsi.v4i2.10830

Prasetyo, E., \& Putra, A. (2021). Implementasi Waterfall Model Dalam Pengembangan Sistem Informasi Eksekutif Penduduk. Journal of Information Systems and Informatics, 3(1), $213-224$. https://doi.org/10.33557/journalisi.v3i1.121

Rosa Ariani, M. S. (2016). Sukamto, Rosa Ariani, Muhammad Shalahuddin. 2016. Rekayasa Perangkat Lunak Terstruktur Dan Berorientasi Objek Edisi 4. Bandung: Informatika.

Syarif, M., \& Nugraha, W. (2020). Pemodelan Diagram UML Sistem Pembayaran Tunai Pada Transaksi ECommerce. Jurnal Teknik Informatika Kaputama (JTIK), 4(1), 70 halaman. http://jurnal.kaputama.ac.id/index.php/JTIK/article/view/240 